\title{
Deconstructing agronomic resource use efficiencies to increase food production
}

\author{
John R. Porter, ${ }^{1}$ Peter J. Thorburn, ${ }^{2}$ Hamish E. Brown, ${ }^{3}$ Edmar I. Teixeira, ${ }^{3}$ Derrick J. Moot, ${ }^{4}$ \\ Annamaria Mills, ${ }^{4}$ Svend Christensen ${ }^{1}$ \\ ${ }^{1}$ Faculty of Sciences, University of Copenhagen, Copenhagen, Denmark; ${ }^{2}$ CSIRO Agriculture, St Lucia Qld, \\ Australia; ${ }^{3}$ New Zealand Institute for Plant and Food Research, Christchurch, New Zealand; ${ }^{4}$ Faculty of \\ Agriculture and Life Sciences, Lincoln University, Lincoln, New Zealand
}

\begin{abstract}
Highlights
- Novel ideosystem method of analysing processes of food production, focussing on resource use efficiencies.

- Interactions between resource use efficiencies are asymmetrical.

- The ideosystem concept portrays how far a production system approaches maximum efficiency.
\end{abstract}

\section{Abstract}

Food production per unit land area needs to be increased, thus

Correspondence: John R. Porter, Faculty of Sciences, University of Copenhagen, 2630 Taastrup, Copenhagen, Denmark. E-mail: jrp@plen.ku.dk

Key words: Crop ideosystem; resource deconstruction; resource use efficiency; Zea mays; Dactylis glomerata; Saccharum officinarum.

Acknowledgements and funding: this work was supported by the MACSUR project of the Danish Strategic Research Council (FACCE - JPI MACSUR - A detailed climate change risk assessment for European agriculture and food security, in collaboration with international projects, 0603-00507B) and the Land Use Change and Intensification project of the New Zealand Institute for Plant and Food Research. We acknowledge van Noordwijk and de Willigen (1986) for their thinking about cropping systems and pensioner Dr Peter D. Jamieson for comments on the paper.

Contributions: JRP, HB and ET developed the theory; DJM, AM and HB provided the data; JRP, HB, ET and SC made the data analyses; JRP, HB, ET, DJM and SC wrote the paper.

Conflict of interests: the authors declare no potential conflict of interests.

See online Appendices for Supplementary materials and data.

Received for publication: 6 July 2020 .

Revision received: 23 February 2021.

Accepted for publication: 9 March 2021.

(C) Copyright: the Author(s), 2021

Licensee PAGEPress, Italy

Italian Journal of Agronomy 2021; 16:1694

doi:10.4081/ija.2021.1694

This article is distributed under the terms of the Creative Commons Attribution Noncommercial License (by-nc 4.0) which permits any noncommercial use, distribution, and reproduction in any medium, provided the original author(s) and source are credited. cropping systems need to use nutrients, water and solar radiation at as close to maximal efficiencies as possible. We deconstruct these efficiencies into their components to define a theoretical crop ideosystem, in which all resource use efficiencies are maximised. This defines an upper biological limit to food production. We then quantify the difference between maximum use efficiencies and those observed in three agronomic systems (maize, cocksfoot, sugarcane) and identify how, in actual farm systems, efficiencies can be raised to raise food production. We find that crop nutrient use efficiency can be limited by low water availability; thus adding nutrients would not raise production but adding water would. The converse situation of water use efficiency being affected by nutrition is not as evident. Ideosystem thinking can be used to define small- and large-scale agronomic systems that optimize water and nutrient use to maximise food production.

\section{Introduction}

Providing food for an expanding human population using lower levels of resource input, and in the face of an increasingly hostile climate (Porter et al., 2014), has led to the notion of sustainable intensification. This posits a simultaneous increase in primary production and resource use efficiencies (Garnett et al., 2013), with the main resources being water, nutrients and solar radiation. Efficiency is defined as the amount of output per unit input (Fischer et al., 2014). Efforts to find mainly genetics-based solutions to increased crop production efficiency in the field have been disappointing (Sinclair and Rufty, 2012), mainly because of a lack of focus on and understanding of whole cropping systems.

We think, as agronomists, that sustainable intensification lacks operationalization and quantification (Garnett et al., 2013). Thus, in this paper we show two things: deconstruction of cropping system intensification into operational and quantifiable resource (water, nitrogen, radiation) use efficiencies, and an assessment of the maximum level of these efficiencies that sets an absolute upper limit to food production from three systems. We measure the sustainability of intensification via the degree of closure in crop nutrient and water cycles and the minimisation of losses. Other tools, such as complex crop models (Ewert et al., 1999; Jones et al., 2003; Holzworth et al., 2014), are too detailed to help policy persons and/or farmers define where efforts would best be focused to raise the sustainable intensification of food production. One 
insight offered by our method is that resource use efficiencies interact asymmetrically and that the efficiency of, for example, nutrient use depends also on water use efficiency. The policy implication is that focussing on raising water use efficiency alone is likely to benefit nutrient use efficiency and contribute to raising crop production without additional nutrient inputs - thus achieving 'more for less'.

Historically, crop physiologists, who understood the processes involved in increasing crop yields, needed to simplify this knowledge and make it accessible to plant breeders. In response to this challenge Colin Donald (Donald, 1962, 1968) developed the notion of the crop ideotype, which represented a crucial conceptual breakthrough in the Green Revolution of the 1960s by defining an 'ideal' structure and form of a crop plant. Thus, an ideotype would be high yielding, be resistant to pest damage and weed competition and would maximise the use of environmental resources such as water, nutrients, light and temperature by, for instance, having erect rather than prostrate leaves. The ideotype concept crucially moved thinking away from regarding crops as composed of individual plants, to the crop as a population with yield as the crop outcome. We wish to expand the ideotype idea and develop a parallel concept of an ideosystem to describe and quantify the properties of sustainable and intensified cropping systems, of which ideotypes may be a component - thus expanding the focus of food production from individual plants to crops to whole farm systems.

\section{Theory}

Increases in yield can occur at many levels in a crop production system. For example, grain yield (i.e. production or yield per area) can be increased by raising any of the elements in the right-hand side of Equation 1. There can be trade-offs between elements, but for the major cereals, raising the number of grains per ear (i.e. total grain sink capacity) has been more important than individual grain size in increasing crop yields (Hay and Porter, 2006).

$$
\frac{\text { Yield }}{\text { Area }} \equiv \frac{\text { Ears }}{\text { Area }} \times \frac{\text { Grains }}{\text { Ear }} \times \frac{\text { Yield }}{\text { Grain }}
$$

Equation 1 is, strictly speaking, a mathematical identity because it deconstructs the element on the left of the ' $\equiv$ ' (equivalence) operator into its component parts (Bennett et al., 2012). This enables us to consider how crop structure and function will influence each of the elements on the right to increase (or decrease) the element on the left. Each of the right-hand side components can increase or decrease yield per unit area, with the net result of yield/area being the trade-off between the three elements on the right of the ' $\equiv$ ' (equivalence) sign. Recently, the identity approach, as the KayaPorter identity, has been used to deconstruct and estimate greenhouse gas emissions from agriculture from 1970, with extrapolation to 2050 (Bennetzen et al., 2016). The advantage of this approach being that emissions can be linked to actual agricultural practices, cropping area and emissions per unit agricultural product.

Transferring this idea to a higher crop system level, identities can also be used to consider resource use efficiencies (Van Noordwijk and De Willigen, 1986; Porter and Christensen, 2013; Wang et al., 2020). Nitrogen use efficiency (NUE) can be deconstructed as follows:

$$
\text { NUE }=\frac{\text { Biomass }}{\text { FertNinputs }} \equiv \frac{\text { SoilAvailableN }}{\text { FertNinputs }} \times \frac{\text { Nuptake }}{\text { SoilAvailableN }} \times \frac{\text { Biomass }}{\text { Nuptake }}
$$

The net effect, as elements in the identity cancel, is NUE defined as biomass per unit of nitrogen input; the conventional and basic definition. As in the components of yield example above, NUE can be raised or lowered via changes in the ratios on the RHS of the 三 sign, with the proviso that the denominator values must be larger than zero. Similarly, water use efficiency (WUE) can be deconstructed as:

WUE $=\frac{\text { Biomass }}{\text { IrrigationInputs }} \equiv \frac{\text { SoilAvailableWater }}{\text { IrrigationInputs }} \times \frac{\text { WaterUptake }}{\text { SoilAvailableWater }} \times \frac{\text { Biomass }}{\text { WaterUptake }}$

In each case, use efficiencies are reduced to NUE = Biomass / FertNIinputs and, similarly, WUE = Biomass/Irrigation inputs, also known as the marginal irrigation WUE (Fischer et al., 2014). The identity for radiation use efficiency (Porter and Christensen, 2013) (Equation 4) can be written as:

$$
R U E=\frac{\text { Biomass }}{\text { SolarRad }} \equiv \frac{\text { InterceptedRad }}{\text { SolarRad }} \times \frac{\text { Photosynthesis }}{\text { InterceptedRad }} \times \frac{\text { Biomass }}{\text { Photosynthesis }}
$$

Each of the elements in the resource use efficiency identities (Equations 2 and 3) can be drawn as four connected quadrants (Van Noordwijk and De Willigen, 1986) (Figure 1). Quadrant A (the fieldcrop quadrant) represents biomass production per unit of resource input and is represented by Biomass/FertNinputs in Equation 2, coming closest to the agronomic definition of resource efficiency (Sinclair and Rufty, 2012). Quadrant B (the soil quadrant; SoilAvailableN/FertNinputs in Equation 2) represents the resource available in the soil per unit of resource input from Quadrant A and has a non-zero intercept because there is usually some water or nutrient in the soil when the crop is planted. Quadrant C (the root quadrant; Nuptake/SoilAvailableN in Equation 2) represents resource uptake per unit resource available in the soil from Quadrant B. Finally, D (the canopy quadrant; Biomass/Nuptake in Equation 2) represents biomass production per unit of resource uptake from Quadrant C. The curvilinear relationship in Quadrant D reflects the biological limits of conversion of nutrient into biomass and will change for different crop species and stage of biomass accumulation (Lemaire and Gastal, 2009). The dashed lines in Quadrants A and $\mathrm{D}$ represent what would happen for crops with excessive resource uptake. A crucial element in Figure 1 are the black lines at angles of $45^{\circ}$, since these represent the $100 \%$ efficiencies in each of the quadrants. A perfect ideosystem would occur if all use efficiencies, for all resources in all quadrants, were found on the $45^{\circ}$ lines, as resource use efficiencies in both a relative (as \% of maximum) and an absolute (as output divided by input) sense are then at maximum. The questions are how close actual cropping systems come to this 'ideal' state and what maximum use efficiencies can be reached and with what consequences for crop biomass production.

The usefulness of the ideosystem concept can be seen by taking the outer black line in Figure 1, which has a higher biomass production than the inner grey line, which has zero added nutrients. However, the inner grey line shows higher resource use efficiency because the biomass per unit nutrient uptake is on the linear part of the curve in Quadrant D. The efficiency associated with the black line is lower because the high inputs cause availability to exceed potential uptake (Quadrant C) and the biomass production per unit uptake reduces at higher uptake levels (Quadrant D). This example shows that high biomass production and high resource use efficiency are not necessarily, and perhaps rarely, connected and makes the point that differences in nutrient resource efficiency needs 
to be determined at the whole, and not part, system level, since differences in component efficiencies at any level in the cropping system can affect biomass and/or food production (Equations 2-4). In order to get an appreciation of the functioning of a whole cropping system one can 'walk' from Quadrant A to B, to C and then to D. Further analytical details of this are given in the Supplementary Material file.

\section{Materials and methods}

The ideosystem concept was illustrated using field experimental data for an arable maize crop (Zea mays L.), a cocksfoot (Dactylis glomerata L.) pasture and sugar cane (Saccharum officinarum L) experiment.

\section{Maize}

Full details of the maize experiments are given elsewhere (Teixeira et al., 2014). Briefly, maize hybrid Pioneer 39G12 was sown into a Templeton silt loam soil in field (2011-12) under a mobile rain shelter (2012-13) to give irrigated and non-irrigated conditions. In the 2011-12 season, three replicates of four $\mathrm{N}$ applications ranging from 0 to $200 \mathrm{~kg} \mathrm{~N} /$ ha were used. Under the rain-shelter, irrigation and non-irrigation treatments were combined with three nitrogen application levels of 0,75 and $250 \mathrm{~kg} \mathrm{~N} / \mathrm{ha}$, with four replicates per treatment. Nitrogen was applied as two or three split dressings and irrigation applied weekly to replace potential evapo-transpiration. Soil mineral nitrogen was measured to $1.5 \mathrm{~m}$ depth just prior to sowing and at harvest and soil moisture was measured to $1.5 \mathrm{~m}$ depth weekly. Available water was calculated as the sum of initial soil water and irrigation inputs.

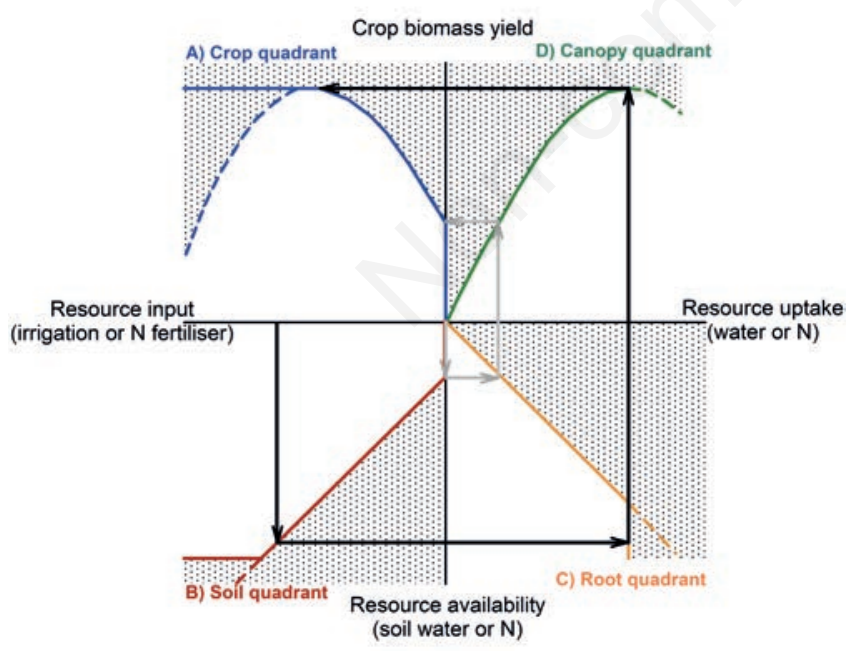

Figure 1. The four Quadrants (A to D) used for visual representation of the nutrient use efficiency of a cropping system. See text for explanation. The lines illustrate the maximum efficiencies possible in each of the quadrants, with the qualification that Quadrant A includes an offset where biomass is positive for zero input and Quadrant B includes an offset to account for soil water or nitrogen as a component of total available resources. Hatched areas indicate locations where the presence of data-points is not possible.

\section{Cocksfoot}

The cocksfoot experiment is described in full by Mills et al. (2009). Briefly, it consisted of a 9-year-old 'Wana' cocksfoot dominant monoculture growing on a Templeton silt loam at Lincoln University, Canterbury, New Zealand. Main plot treatments were dryland (non-irrigated) or fully irrigated to maintain the actual soil moisture deficit at $<50 \mathrm{~mm}$ in the top $0.5 \mathrm{~m}$ of the soil profile. Subplots were $\mathrm{N}$ fertiliser, applied as urea, at $0 \mathrm{~kg} \mathrm{~N} / \mathrm{ha} / \mathrm{yr}$ or 800 $\mathrm{kg} \mathrm{N} / \mathrm{ha} / \mathrm{yr}$ in the 2003/2004 growth season (30 September 2003 to 5 October 2004) applied in split applications of $100 \mathrm{~kg} \mathrm{~N} / \mathrm{ha}$. The rate of $\mathrm{N}$ fertiliser was increased to $1600 \mathrm{~kg} \mathrm{~N} / \mathrm{ha} / \mathrm{y}$ for the second growth season based on results from the first year. The four treatments were replicated three times (Mills et al., 2009). Biomass and nitrogen were measured at the end of 26 - 53 day regrowth periods giving 22 measurement dates throughout the trial. Soil mineral nitrogen was not measured so it was not possible to obtain actual values of soil available $\mathrm{N}$ for each re-growth period. Instead, soil available $\mathrm{N}$ was calculated as the sum of fertiliser inputs and the $\mathrm{N}$ uptake measured in the zero $\mathrm{N}$ treatments, assuming this gives an adequate representation of mineral $\mathrm{N}$ that is available during the re-growth period. Biomass, Fertiliser N, Soil available N and N uptake were normalised by the amount of thermal time (base temperature $=0^{\circ} \mathrm{C}$ ) accumulated during the rotation to remove distortions caused by regrowth duration and time of year.

\section{Sugarcane}

The experimental site for Saccharum officinarum was 3.5 ha in size and located approximately $9 \mathrm{~km}$ north of Bundaberg, Australia in a field that had been under sugarcane for longer than 40 years. In the two years prior to the trial, the site was levelled and fallowed. The experiment consisted of six $\mathrm{N}$ treatments replicated three times in a randomised block design. Each treatment plot was approximately $9.4 \mathrm{~m}$ wide (six rows spaced $1.57 \mathrm{~m}$ apart) and 200 $\mathrm{m}$ long, with an average area of 0.2 ha. Soils at the site have sandy

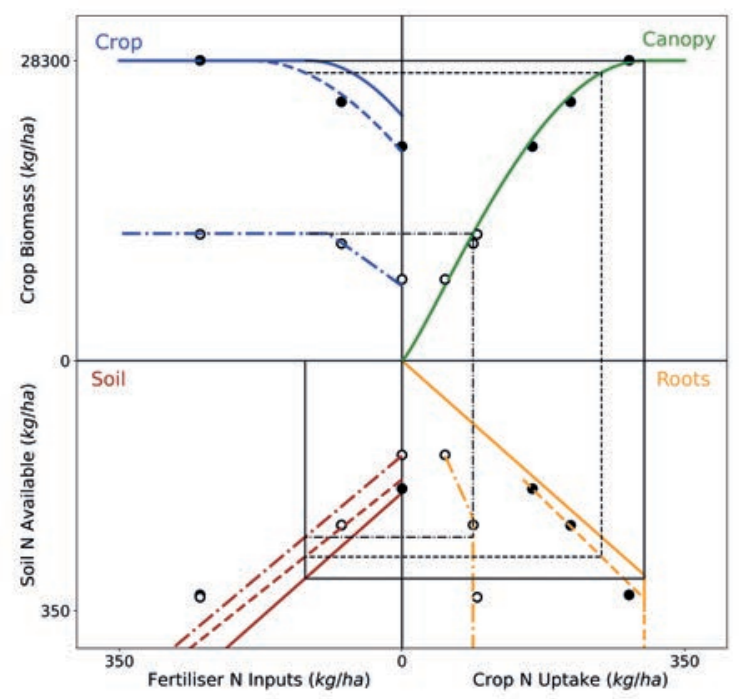

Figure 2. Analysis of nitrogen use efficiency (NUE) in maize crops (A) for the high $\mathrm{N}$ input treatment ("X") in response to irrigated (closed circles) and non-irrigated (open circles) conditions. Solid lines (Quadrants B, C, D) illustrate the identity ratios for a perfectly efficient system. Quadrant line colours in Figure 2 are the same as those in Figure 1, to help readers. 
loam to sandy light clay A horizons, $0.4-0.5 \mathrm{~m}$ deep. The B horizons graded in texture across the site from sandy light clay in the first block to medium clay in the third block, with the heavier textured soil being susceptible to waterlogging (Thorburn et al., 2003).

\section{Results}

\section{Maize}

Figure 2 shows the four quadrants for a maize crop grown with and without irrigation under different nitrogen inputs. Overall the highest $\mathrm{N}$ treatment $(250 \mathrm{~kg} \mathrm{~N} / \mathrm{ha})$ had a NUE of 54.1 and $65.9 \mathrm{~g}$ of grain per $\mathrm{kg}$ of $\mathrm{N}$ for the irrigated and dryland treatments, respectively. To determine the source of these differences we trace the 'walk path' of the data-points for this highest $\mathrm{N}$ treatment for both irrigated and dryland conditions through the quadrants (grey horizontal and vertical lines). A line is fitted by eye to the observed values in Quadrant B (the Soil quadrant), the slope of which represents $\varepsilon_{\mathrm{S}}$, which is the relation between $\mathrm{N}$ input and $\mathrm{N}$ available (0.7; see Supplementary Material) which differs little between the irrigated and non-irrigated treatments, but is well below the potential. The reason for loss in efficiency in this quadrant could be via leaching or gaseous losses from applied N. In Quadrant C, the observed data for the irrigated crops were close to the optimal line $\left(\varepsilon_{\mathrm{R}}=0.9\right.$; see Supplementary Material) but the line fitted to the observed data for the non-irrigated treatments had an $\varepsilon_{R}$ of 0.4 . The data for the treatment with the highest $\mathrm{N}$ input deviated below the line fitted to the other two treatments because water stress limited potential biomass production and so limited maximum $\mathrm{N}$ uptake (X $X_{\text {Umax }}$, Equation 8, see Supplementary Material) to $90 \mathrm{kgN} / \mathrm{ha}$.

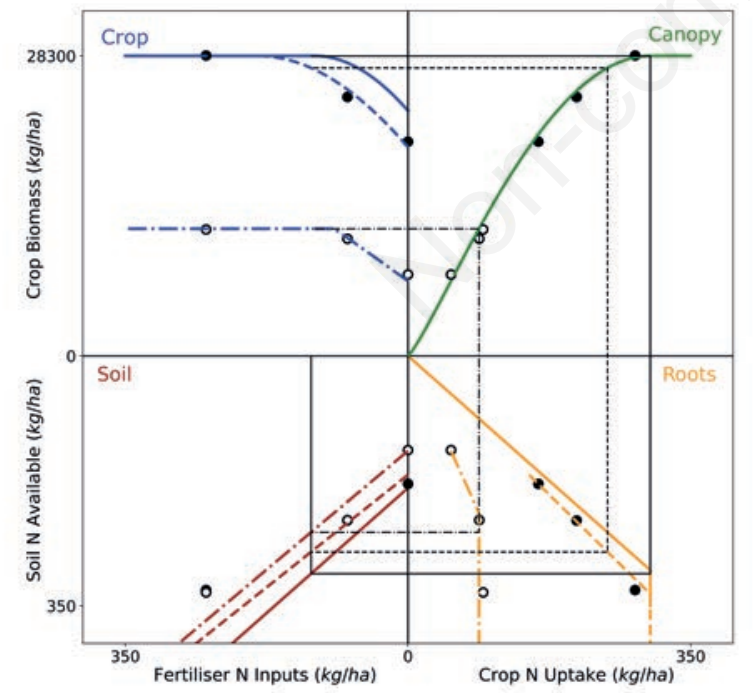

Figure 3. Analysis of nitrogen use efficiency (NUE) in cocksfoot pastures (A) for $\mathbf{N}$ fertiliser inputs in response to irrigated (open circles) and non-irrigated (closed circles) conditions. Solid lines (Quadrants B, C, D) illustrate the identity ratios for a perfectly efficient system. Dashed-dotted line represents lower boundary of data-points in relation to the ideosystem; dashed line the upper boundary. Quadrant line colours in Figure 3 are the same as those in Figure 1, to help readers.
Thus, the paths for the irrigation treatments diverge in this quadrant. In quadrant $\mathrm{D}$, all treatments conformed to the same biomass per $\mathrm{N}$ uptake relationship ( $\gamma=1.2, \mathrm{~B}_{\max }=28300 \mathrm{~kg} / \mathrm{ha}$; see Supplmentary Material). The net result of the walk through Quadrants B $\rightarrow D$, turning a right angle at the appropriate point in each gives the differences in biomass per unit of $\mathrm{N}$ input seen in Quadrant $\mathrm{A}$. Thus, differences in NUE in response to irrigation treatments (A) are mostly attributed to (1) differences in $\varepsilon_{R}$ (Equation 8, see Supplementary Material file) and (2) the maximum $\mathrm{N}$ uptake in response to water availability).

For water use efficiency a different situation occurs (Figure 2) with values of 16.6 and $21.8 \mathrm{~kg}$ of grain per mm of water for lowest $(0 \mathrm{kgN} / \mathrm{ha})$ and highest $(250 \mathrm{kgN} / \mathrm{ha}) \mathrm{N}$ application treatments in the irrigated crops. We trace the 'walk path' of the data-points for these treatments to identify the source of these differences and see the $\mathrm{N}$ treatments had a small effect on the $\varepsilon_{\mathrm{R}}, 0.73$ for high $\mathrm{N}$ and 0.67 for zero $\mathrm{N}$. The main effect of $\mathrm{N}$ is on the shoot component (D) where zero $\mathrm{N}$ treatments produce less biomass ( $\mathrm{B}_{\max }$ of 28300 and $18800 \mathrm{~kg} / \mathrm{ha}$ for irrigated and dryland treatments, respectively), resulting in a lower WUE for the zero $\mathrm{N}$ treatment. The overall conclusion is that the relationship between NUE and WUE is asymmetric when it comes to defining the influence of the one resource on the other. Water availability affects NUE more than nitrogen availability affects WUE.

\section{Cocksfoot}

In Figure 3 we show the upper (solid lines) and lower boundaries (dashed lines) of the population of data-points in response to $\mathrm{N}$ availability for cocksfoot. Readers are invited to add the pathways around the figure for the non-irrigated and irrigated treatments, beginning at the same level of $\mathrm{N}$ input. The point of arrival on the biomass identity axis (D) represents the production

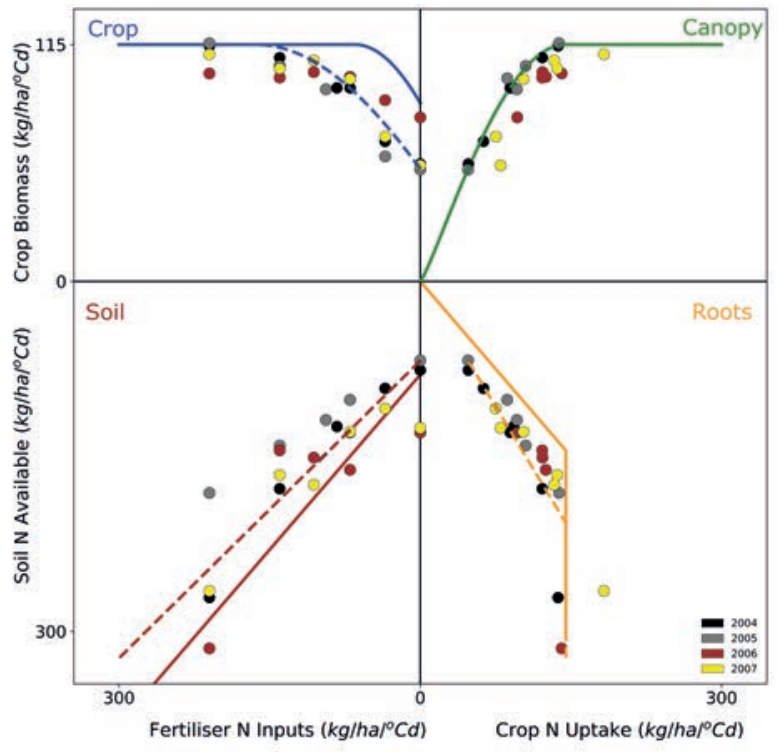

Figure 4. Analysis of nitrogen use efficiency (NUE) in sugarcane crops from 2004-2007, points corresponding to indicated colours. Solid lines (Quadrants B, C, D) illustrate the identity ratios for a perfectly efficient system. Quadrant line colours in Figure 4 are same as those in Figure 1, to help readers. 
that could be expected with the starting level of inputs (B) and with the efficiencies encountered in the pathway round the whole system. The analysis shows that there is considerable variation in the agronomic $\mathrm{N}$ response achieved in the field, largely due to inefficiencies in the soil component of the cropping system.

\section{Sugarcane}

Cane yields were lowest in the N0 treatment in all crops, but it was only in the three ratoon crops that yield responses to $\mathrm{N}$ were significant (Figure 4; $\mathrm{P}<0.05$ ). Cane yields were highest in the 120 $\mathrm{kgN} / \mathrm{ha}$ or the $240 \mathrm{kgN} /$ ha treatments; however, cane yields in the $120 \mathrm{kgN} / \mathrm{ha}, 160 \mathrm{kgN} / \mathrm{ha}$ and $240 \mathrm{kgN} / \mathrm{ha}$ treatments were not significantly greater than that in the $80 \mathrm{kgN} / \mathrm{ha}$ treatment. Wet weather during the growth phase (October-March), reduced radiation interception and caused waterlogging in parts of the experimental site. We invite readers to develop their own 'walks' around each of the crop quadrants.

\section{Discussion}

We have proposed a novel method to simplify the complexity of processes leading to the primary production of food by focussing on the essentials of resource use efficiencies and showing that their interactions are asymmetrical. This is important because it means that increases in production from one factor, such as nutrition, can lead to apparent increases in resource use efficiency of another factor like water. Via the idea of ideosystems, we have shown how lower levels of nutrient inputs can lead to higher levels of crop production (i.e. 'more for less') but this requires high levels of other resource efficiencies such as water use. The practical and policy application of the ideosystem concept could be in three areas. First, the identity method in the context of an ideosystem portrays quantitatively the degree to which a production system approaches maximum efficiency and, more importantly, what is required to improve system resource use efficiency and thus food and fodder production. An important message is that the efficiency of one management factor depends on others (such as between NUE and irrigation) and that maximum efficiency is attained when all efficiencies are at maximum.

However, efficiencies need to be viewed in absolute terms since we need to know how much crop yield requires how much resource. Recent synthesis of efficiencies in relation to food security has shown that maize has reached a water use efficiency of $c a .26 \mathrm{~kg}$ grain $/ \mathrm{mm}$ evapotranspiration and wheat $c a .15-19 \mathrm{~kg}$ grain $/ \mathrm{mm}$ in the USA and China. If maximum photosynthesis can be increased without, at the same time, increasing evapotranspiration by increasing stomatal conductance, then WUE can rise further. Such a response at the crop level could be represented in Equation 3. Maximum current absolute levels for NUE in maize in the USA are about $60-70 \mathrm{~kg}$ grain $/ \mathrm{kg} \mathrm{N}$ (Fischer et al., 2014) and this can be deconstructed into uptake efficiency (i.e. as portrayed in Quadrant $\mathrm{C}$ in Figure 1) and the utilization efficiency of grain production from $\mathrm{N}$ taken up by the crop (Hay and Porter, 2006; Fischer et al., 2014), as portrayed in Quadrant D in Figure 1.

\section{Conclusions}

We believe that the identity concept may be helpful in advisory work and a spreadsheet is available (see Supplementary Material and SupplementaryFile_1.xlsx), which allows the effect of different use efficiencies to be visualized. We think that the ideosystem idea has a role to play in the education of future agronomists and crop physiologists and communication with policy makers, since the concept has a combination of quantitative and indicative simplicity allied to relevance for practical farming that they may find useful. The fact that identities are applicable at many scales could facilitate their usefulness to policy - either in its formulation or assessment. Finally, the idea can serve as an integrating method for assessing the outcomes of genetic modification of crops grown in the field or laboratory. Such putative changes could be, for instance, in the efficiency of root structure and function or in biomass production. Agronomic science requires field based experiments since crops are grown in a field in a variety of soils and with a range of management. The identity approach and the use of the ideosystem concept facilitate integration between laboratory and field in a quantitative and robust manner.

\section{References}

Bennett AJ, Bending GD, Chandler D, Hilton S, Mills P, 2012. Meeting the demand for crop production: the challenge of yield decline in crops grown in short rotations. Biol. Rev. 87:52-71.

Bennetzen EH, Smith P, Porter JR, 2016. Decoupling of greenhouse gas emissions from global agricultural production: 1970-2050. Global Change Biol. 22:763-81.

Donald CM, 1962. In search of yield. J. Aust. Inst. Agric. Sci. 28:171-78.

Donald CM, 1968. The breeding of crop ideotypes. Euphytica. 17:385-403.

Ewert F, van Oijen M, Porter JR, 1999. Simulation of growth and development processes of spring wheat in response to $\mathrm{CO}_{2}$ and ozone for different sites and years in Europe using mechanistic crop simulation models. Eur. J. Agron. 10:231-47.

Fischer RA, Byerlee D, Edmeades GO, 2014. Crop yields and global food security: will yield increase continue to feed the world? ACIAR Monograph No. 158. Australian Centre for International Agricultural Research, Canberra, Australia.

Garnett T, Appleby MC, Balmford A, Bateman IJ, Benton TG, Bloomer P, Godfray HCJ, 2013. Sustainable intensification in agriculture: premises and policies. Science. 341:33-4.

Hay RKM, Porter JR, 2006. The physiology of crop yield. (2nd ed.). Blackwell Publishing Ltd, Oxford, UK.

Holzworth DP, Huth NI, deVoil PG, Zurcher EJ, Herrmann NI, McLean G, Keating BA, 2014. APSIM - Evolution towards a new generation of agricultural systems simulation. Envt. Model. Software. 62:627-50.

Jones JW, Hoogenboom G, Porter CH, Boote KJ, Batchelor WD, Hunt LA, Ritchie JT, 2003. The DSSAT cropping system model. Eur. J. Agron. 18:235-65.

Lemaire G, Gastal F, 2009. Quantifying crop responses to nitrogen deficiency and avenues to improve nitrogen use efficiency. In: V.O. Sadras \& D.F. Calderini (Eds.), Crop physiology applications for genetic improvement and agronomy. Academic Press Ltd., Amsterdam, NL and London, UK, pp. 171-211.

Mills A, Moot DJ, Jamieson PD, 2009. Quantifying the effect of nitrogen of productivity of cocksfoot (Dactylis glomerata L.) pastures. Eur. J. Agron. 30:63-9.

Porter JR, Christensen S, 2013. Deconstructing crop processes and models via identities. Plant Cell Environ. 36:1919-25.

Porter JR, Xie L, Challinor AJ, Cochrane K, Howden SM, Iqbal MM, Lobell DB, Travasso MI, 2014. Food security and food production systems. In: C.B. Field, V.R. Barros, D.J. Dokken, K.J. Mach, M.D. Mastrandrea, T.E. Bilir, M. Chatterjee, K.L. Ebi, Y.O. Estrada, R.C. Genova, B. Girma, E.S. Kissel, A.N. 
Levy, S. MacCracken, P.R. Mastrandrea, L.L. White (Eds.), Climate change 2014: impacts, adaptation and vulnerability. part A: global and sectoral aspects. Contribution of working group II to the fifth assessment report of the Intergovernmental Panel on Climate Change. Cambridge University Press, Cambridge, UK and New York, USA, pp. 485-533.

Sinclair TR, Rufty TW, 2012. Nitrogen and water resources commonly limit crop yield increases, not necessarily plant genetics. Global Food Sec. 1:94-8.

Teixeira EI, George M, Herreman T, Brown H, Fletcher A, Chakwizira E, Noble A, 2014. The impact of water and nitrogen limitation on maize biomass and resource-use efficiencies for radiation, water and nitrogen. Field Crops Res. 168:109-18.
Thorburn PJ, Dart IK, Biggs IM, Baillie CP, Smith MA, Keating BA, 2003. The fate of nitrogen applied to sugarcane by trickle irrigation. In: P.J. Thorburn, K.L. Bristow, J. Annandale (Eds.), Micro-irrigation: advances in system design and management. Irrig. Sci. 22:201-9.

Van Noordwijk M, De Willigen P, 1986. Quantitative root ecology as element of soil fertility theory. Neth. J. Agric. Sci. 34: 273-81.

Wang X, Christensen S, Svensgaard J, Jensen SM, Liu F, 2020. The effects of cultivar, nitrogen supply and soil type on radiation use efficiency and harvest index in spring wheat. Agronomy. 10:1391-403. 